acquired valvular heart disease, 59 cases of congenital heart disease, and 10 cases of non-coronary cardiomyopathy were discovered. In addition, 58 cases of other forms of heart disease were found.

The value, difficulties encountered, and limitations of this method of detecting heart disease are discussed. The factors necessary for success in an exercise of this type are mentioned.

From the experience gained in this survey it is thought worth while to attempt the detection of heart disease in combination with a survey for the discovery of chest diseases.

We are indebted to the general practitioners of East Suffolk for their help and co-operation in this survey and to the administrative staff of the East Suffolk Community $X$-ray Survey Unit for their help in carrying it out ; to Miss J. L. Bond for clerical and secretarial help ; to Dr. S. T. Gray, M.O.H. for East Suffolk, for his support and co-operation; to Dr. A. Gee, Chief School Medical Officer, Lowestoft, for his help and co-operation in the Lowestoft area : to Dr. J. B. Ewen, Senior Administrative Medical Officer, East Anglian Regional Hospital Board, for his help and support during the survey ; to Dr. C. J. Stewart, consultant chest physician, Ipswich Chest Clinic, for providing the facilities and for his generous support of the project ; to Dr. W. A. Oliver, physician, Norfolk and Norwich Hospital, for investigating the cases in the Lowestoft area ; and to Mr. B. B. Milstein, thoracic surgeon to East Anglian Regional Hospital Board and Addenbrooke's Hospital, Cambridge, for operating on the majority of the cases needing surgical treatment and for his help in the preparation of this paper.

\section{REFERENCES}

Adrian Committee (1959). Radiological Hazards to Patients. Interim Report of Committee. H.M.S.O., London.

Bostock, M. I. and Morris, W. (1952). Cand. med. Ass. F., 66, 126.

Flancher, L. H. (1948). Amer. Rev. Tuberc., 57, 375.

Fleming, H A (1959). Circulation, 19, 856.

Heather, A Segal B., 25, 451.

Maclean, A., and Rogen, A (1949). Ibid., 11, 264.

Mathisen, A. K., Mogris, W., and Wilson, G. B. (1950). Amer. Heart F. 39, 505 .

Miller, R. A., Smith, J., Stamler, J., Hahneman, B., Paul, M. H., Abrams, I., Hait, G., Edelman, J., Willard, J., and Stevens, W. (1962). Circulation, 25, 85.

Morton, W., Beaver, M. E. N., and Arnold, R. C. (1959a). F. Amer. med. Ass., 169, 1163

Ass., 169, 1163. . Cleere, R. L., and Dodge, H. J. (1959b). Ibid. $169,1169$.

Porte, D. (1952). Ann. intern. Med., 36, 603.

Porte, D. (1952). Ann. intern. Med., 36, 603.

Schwartz, B., and Berman, B. (1952). A. A. Amer. T. (1951). Amer. Heart \%., 42,355 .

Smith, J. M., Miller, R. A., Marienfeld, C., Hahneman, B., and Willard, J.' (1959). Circulation, 20, 887

West, H. F. (1946). Amer. Rev. Tuberc., 54, 465.

\title{
Oral Respiratory Stimulants in Chronic Respiratory Failure
}

\section{Double-blind Controlled Trial of Amiphenazole and Dichlorphenamide}

\author{
W. MCC. NELSON,* M.в., в.CH., в.A.o. ; WILlIAM F. M. WALLACE,* M.B., в.CH., B.SC., B.A.o.
}

The long-term treatment of chronic bronchitis is very unsatisfactory. Although many drugs are used in this condition, it is not usually possible to halt the steady progression of the disease. A recent development has been the widespread promotion of oral respiratory stimulants for use in chronic bronchitis, despite the fact that there is little evidence that they are of value in this condition (Scadding, 1963).

In the assessment of a drug used in chronic bronchitis, a disease which undergoes marked spontaneous variations from time to time, a double-blind controlled trial is essential. However, most of the reports concerning the use of oral respiratory stimulants have been of uncontrolled trials.

This paper reports a double-blind controlled trial of two commonly used respiratory stimulants in patients with chronic respiratory failure. Both objective and subjective assessments have been made, and side-effects have been recorded. Since objective evidence of respiratory failure must be present before improvement may be objectively assessed, only patients with carbon dioxide retention or reduced arterial oxygen saturation were admitted to the trial.

\section{Plan of Trial and Methods Used}

The two commonly used oral respiratory stimulants, amiphenazole (Daptazole) and dichlorphenamide (Daranide, Oratrol), were chosen for assessment. Active and placebo tablets were identical in appearance, and their identity was unknown to the patients and to the assessors during the trial.

\footnotetext{
* Department of Therapeutics and Pharmacology, the Queen's University
} of Belfast.
Four tablets a day were taken, the total daily dose of amiphenazole being $400 \mathrm{mg}$., and of dichlorphenamide $200 \mathrm{mg}$. These are the standard doses recommended by the manufacturers.

Each patient took the two active drugs and the placebo in three consecutive fortnights, the order of the drugs being varicd so that all possible sequences were equally represented. Assessments were made at the end of each fortnight of treatment, all observations on the same patient being made by the same observer.

The patients chosen for the trial had severe chronic bronchitis and were all disabled but ambulant. They attended as outpatients. All had objective signs of respiratory failure when in a steady state, with either an arterial oxygen saturation of less than $90 \%$ or a mixed venous carbon dioxide tension $\left(\mathrm{PCO}_{2}\right)$ of $53 \mathrm{~mm}$. Hg or more.

Nineteen patients began the trial, but only 12 were included in the final analysis. In one patient results were not obtained owing to illness of the observer. Three others discontinued treatment because of side-effects. The remaining three complained of side-effects, but in addition developed intercurrent illness. Two of them had exacerbations of their chronic bronchitis, and the third developed congestive heart failure, was admitted to hospital, and died with a myocardial infarction.

Of the 12 patients finally included in the trial, 10 were men and two were women. Their ages ranged from 40 to 66 , and averaged 52 years.

Arterial oxygen saturation was measured by ear oxymetry with an Atlas Universal Oxymeter. Hyperaemia of the ear was induced with a cream containing as active ingredients nonylic 
acid vanillylamide $0.4 \% \mathrm{w} / \mathrm{w}$ and $\beta$-butoxyethyl ester of nicotinic acid $2.5 \% \mathrm{w} / \mathrm{w}$.

Mixed venous $\mathrm{PCO}_{2}$ was determined by the rebreathing method described by Campbell and Howell (1960, 1962). On each occasion two separate measurements were made. Each gas sample was analysed in duplicate with a modified Haldane apparatus (Campbell, 1960). The mean of the two measurements is reported.

Ventilation was measured over a two-minute period using a Wright respirometer. The mean of two measurements is reported.

Plasma sodium, potassium, chloride, and $\mathrm{CO}_{2}$-combining power $\left(\mathrm{CO}_{2}\right.$ C.P. $)$ and blood urea were all estimated using a Technicon AutoAnalyzer. Plasma specific gravity (P.S.G.) was estimated by the copper sulphate method.

At each visit patients were questioned about symptoms and side-effects, using a standard set of questions. At the last visit they were asked to state during which of the three fortnights they felt best.

\section{Results}

Placebo and basal results were compared for each variable, using a " $t$ " test of statistical significance. Differences where $P$ was less than 0.05 were considered significant. In no case was there a significant difference between basal and placebo results. The effects of the active drugs are summarized in Tables I and II. ${ }^{1}$ Only 10 patients are included in Table II, since two were unable to complete the course of dichlorphenamide. Table III shows what the patients thought of the drugs.

Details of adverse symptoms are given in Table IV. This includes the symptoms reported by the seven patients not eventually included in the trial. Since most of them discontinued treatment because of adverse symptoms, their omission would have given an unrealistically low incidence of these side-effects.

The effects of the two drugs are best considered separately.

Amiphenazole.-The results are given in Table I. Compared with the placebo, there was a slight increase in arterial oxygen saturation from $86.2 \%$ to $86.7 \%$, and the mixed venous $\mathrm{PCO}_{2}$

TABLE I.-Summary of Effects of Amiphenazole. Mean of Results in 12 Patients

\begin{tabular}{|c|c|c|c|c|c|}
\hline Variable & & Placebo & $\begin{array}{l}\text { Amiphen- } \\
\text { azole }\end{array}$ & Difference & $\begin{array}{l}\text { Value of } P \\
\text { if }<0.05\end{array}$ \\
\hline 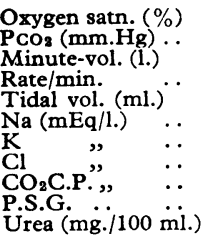 & $\begin{array}{l}\ldots \\
\cdots \\
\cdots \\
\cdots \\
\cdots \\
\cdots \\
\cdots\end{array}$ & $\begin{array}{c}86 \cdot 2 \\
61 \cdot 9 \\
11 \cdot 3 \\
18 \cdot 8 \\
636 \\
143 \cdot 3 \\
4 \cdot 51 \\
97 \cdot 8 \\
32 \cdot 0 \\
1027 \cdot 5 \\
23 \cdot 6\end{array}$ & $\begin{array}{c}86 \cdot 7 \\
61 \cdot 0 \\
11 \cdot 2 \\
18 \cdot 8 \\
622 \\
142 \cdot 5 \\
4 \cdot 28 \\
100 \cdot 1 \\
29 \cdot 2 \\
1028 \cdot 2 \\
24 \cdot 8\end{array}$ & $\begin{array}{l}+0.5 \\
-0.9 \\
-0.1 \\
-14 \\
-0.8 \\
-0.23 \\
+2.3 \\
-2.8 \\
+0.7 \\
+1.2\end{array}$ & $\begin{array}{c}\bar{E} \\
= \\
= \\
= \\
\bar{E} \\
0.05>0.02 \\
0.05>P>0.02\end{array}$ \\
\hline
\end{tabular}

fell from 61.9 to $61 \mathrm{~mm}$. Hg. These differences were not statistically significant, nor are they of an order likely to be of any clinical importance. The only significant effects were a fall in the plasma $\mathrm{CO}_{2}$ C.P. from 32 to $29.2 \mathrm{mEq} / \mathrm{l}$. and a rise in the P.S.G. from 1027.5 to 1028.2. Amiphenazole did not produce symptomatic improvement in any more patients than did the placebo (Table III). As shown in Table IV, adverse symptoms were only slightly more frequent with amiphenazole than with the placebo.

Dichlorphenamide.-The results are given in Table II. There was a mean rise in oxygen saturation from $86.8 \%$ to $90.9 \%$, and a mean fall in mixed venous $\mathrm{PCO}_{2}$ from 60.5 to $55.1 \mathrm{~mm} . \mathrm{Hg}$. These changes were highly significant $(\mathrm{P}<0.02$

${ }^{1}$ Full details of the results for each patient are available, and photostat copies will be forwarded on request. and $\mathrm{P}<0.01$ respectively). Although the minute-volume did not change significantly, the respiratory rate fell, and the tidal volume rose from 653 to $769 \mathrm{ml}$. The plasma potassium fell from 4.7 to $4.07 \mathrm{mEq} / 1$, the $\mathrm{CO}_{2}$ C.P. fell from 31.6 to 26.5 $\mathrm{mEq} / 1$, and the blood urea rose from 24.4 to $29.9 \mathrm{mg}$. $/ 100 \mathrm{ml}$. No significant changes were observed in the plasma sodium and chloride or in the P.S.G. Dichlorphenamide was not superior to the placebo in its symptomatic effect (Table III). Ten of the 17 patients who took dichlorphenamide reported adverse effects (Table IV), and seven of these discontinued the drug before the completion of the two-week trial period. The commonest symptoms were headaches and gastro-intestinal disturbances.

TAble II.-Summary of Effect of Dichlorphenamide. Mean of Results

\begin{tabular}{|c|c|c|c|c|c|}
\hline Variable & & Placebo & $\begin{array}{c}\text { Dichlor- } \\
\text { phenamide }\end{array}$ & Difference & $\begin{array}{l}\text { Value of } P \\
\text { if }<0.05\end{array}$ \\
\hline 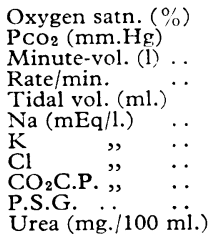 & $\begin{array}{l}\cdots \\
\cdots \\
\cdots \\
\cdots \\
\cdots \\
\cdots \\
\cdots\end{array}$ & $\begin{array}{c}86 \cdot 8 \\
60 \cdot 5 \\
11 \cdot 9 \\
19 \cdot 4 \\
653 \\
144 \cdot 0 \\
4 \cdot 70 \\
98 \cdot 8 \\
31 \cdot 6 \\
1027 \cdot 4 \\
24 \cdot 4\end{array}$ & $\begin{array}{c}90 \cdot 9 \\
55 \cdot 1 \\
12 \cdot 9 \\
17 \cdot 8 \\
769 \\
141 \cdot 3 \\
4 \cdot 07 \\
101 \cdot 4 \\
26 \cdot 5 \\
1027 \cdot 3 \\
29 \cdot 9\end{array}$ & $\begin{array}{c}+4.1 \\
-5.4 \\
+1.0 \\
-1.6 \\
+116 \\
-2.7 \\
-0.63 \\
+2.6 \\
-5.1 \\
-0.1 \\
+5.5\end{array}$ & $\begin{array}{l}0.02>\mathbf{P}>0.01 \\
0.01>\mathbf{P}>0.001 \\
0.02>\overline{\mathbf{P}}>0.01 \\
0.01>\mathbf{P}>0.001 \\
0.01>\overline{\mathbf{P}}>0.001 \\
0.01>\overline{\mathbf{P}}>0.001 \\
0.05>\overline{\mathbf{P}}>0.02\end{array}$ \\
\hline
\end{tabular}

* Nine patients in the case of oxygen saturation.

TABle III.-Summary of Symptomatic Effects in 12 Patients

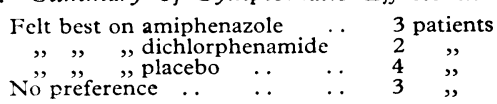

TABLE IV.-Summary of Adverse Symptoms

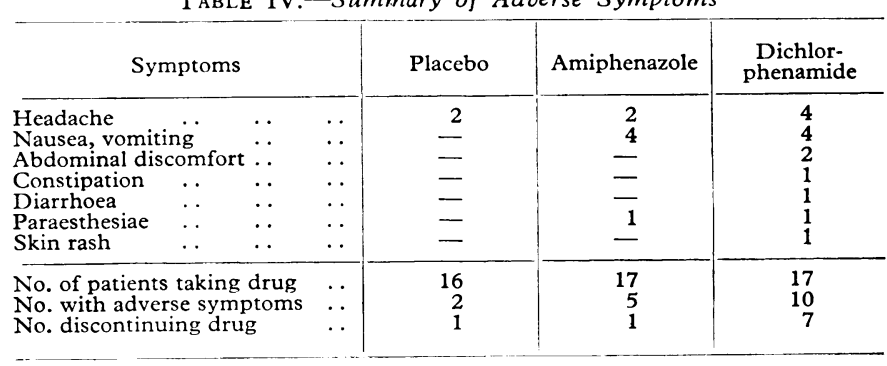

\section{Discussion \\ Again each drug is considered in turn.}

\section{Amiphenazole}

This drug has been reported to cause a short-term increase in ventilation and a fall in $\mathrm{PCO}_{2}$ in patients suffering from acute respiratory failure due to an exacerbation of chronic bronchitis (Little, 1962 ; Hughes, 1963). There have, however, been no controlled trials of its value in ambulant chronic bronchitic patients, as pointed out by Scadding (1963).

Our results showed no significant improvement in the blood gases or in the symptoms at the end of a fortnight's treatment. If the drug is indeed effective in short-term therapy (several hours or days), our findings could be explained by a rapidly developing tolerance to the drug, as suggested by Hughes (1963). The fall in the $\mathrm{CO}_{2}$ C.P. and rise in the P.S.G. suggest that amiphenazole may produce a bicarbonate diuresis, as does dichlorphenamide. The rise in plasma chloride and falls in plasma sodium and potassium, though not statistically significant, would seem to support this view. Although side-effects were not serious in the present study, widespread lichenoid skin eruptions have been reported with the use of higher doses and for longer periods (Baker and Pegum, 1963 ; Hughes, 1963). 
In summary, amiphenazole did not produce any significant change in either the symptoms or the blood gases of the patients studied.

\section{Dichlorphenamide}

A number of workers have reported on the effects of this drug in chronic respiratory failure (Naimark, Brodovsky, and Cherniack, 1960 ; Simpson, 1961 ; McNicol and Pride, 1961 ; Dorris, Olivia, and Rodman, 1964). In all these trials the dose of dichlorphenamide was the same as in the present study$200 \mathrm{mg}$./day. Only one of these trials was controlled (McNicol and Pride, 1961).

The earlier uncontrolled trials of Naimark et al. and Simpson suggested that dichlorphenamide was of considerable value in chronic respiratory failure and produced marked symptomatic improvement in most patients. Appreciable improvement in the blood gases was also reported. Side-effects did not appear to be serious in the first of these trials, but, in the second, four out of seven patients had to stop treatment because of them.

$\mathrm{McNicol}$ and Pride, in their double-blind crossover trial in 17 patients, reported a mean fall in mixed venous $\mathrm{PcO}_{2}$ from 65 to $57 \mathrm{~mm}$. $\mathrm{Hg}$ at the end of two weeks, the value being $58 \mathrm{~mm}$. $\mathrm{Hg}$ at the end of four weeks. Seven patients claimed to be less dyspnoeic while on dichlorphenamide, but six made similar claims while on the placebo. Side-effects were reported in all but one patient, and five patients had to abandon the drug or reduce its dosage. These workers were not enthusiastic about the value of dichlorphenamide in chronic respiratory failure.

Dorris et al. (1964) reported on 11 patients treated in hospital when their condition was believed stable. After 10 to 14 days on dichlorphenamide their arterial oxygen saturation had risen from 82.9 to $86.5 \%$, and their mean arterial $\mathrm{PCO}_{2}$, considered by Campbell and Howell (1960) to be approximately $6 \mathrm{~mm}$. lower than the mixed venous $\mathrm{PCO}_{2}$, had fallen from 54 to $45 \mathrm{~mm}$. $\mathrm{Hg}$. Symptoms and side-effects are not discussed in detail, but the authors concluded that there is little or no place for the use of carbonic anhydrase inhibitors in the treatment of respiratory acidosis.

The changes in arterial oxygen saturation and mixed venous $\mathrm{PCO}_{2}$ in our trial were of the same order as in the above papers (Table II).

The deeper breathing observed would appear to account for the changes in the blood gases. The marked fall in $\mathrm{CO}_{2}$ C.P. is in keeping with a bicarbonate diuresis and resultant acidosis. Dorris et al. (1964) considered that this acidosis was responsible for the change in ventilation observed. The mechanism of action of dichlorphenamide would appear to be :

carbonic
anhydrase
inhibition $\rightarrow \begin{gathered}\text { bicarbonate } \\ \text { diuresis }\end{gathered} \rightarrow \begin{aligned} & \text { metabolic } \\ & \text { acidosis }\end{aligned} \rightarrow \begin{gathered}\text { increased } \\ \text { tidal } \\ \text { volume }\end{gathered} \rightarrow \begin{gathered}\text { return of } \\ \text { blood gases } \\ \text { towards normal }\end{gathered}$

Those authors thought, however, that the decreased blood $\mathrm{PCO}_{2}$ may give a false impression of improvement, since the tissue $\mathrm{PCO}_{2}$ may not fall correspondingly because inhibition of carbonic anhydrase may interfere with the excretion of $\mathrm{CO}_{2}$ from the cell. The raised arterial oxygen saturation would, however, appear to result in a raised tissue oxygen level.

Perhaps one of the most important findings of the present trial was the confirmation of McNicol and Pride's (1961) suggestion that dichlorphenamide does not make the patients feel any better (Table III). It would appear that any beneficial effects of the improved blood gases are counterbalanced by the adverse metabolic changes. In addition, the deeper breathing induced may increase the sensation of dyspnoea.

Our trial confirmed the high incidence of severe adverse symptoms found by McNicol and Pride (1961) and by Simpson (1961). Although most of our patients were very anxious to give the new therapy a trial, 7 out of 17 were unable to complete the fortnight's course. Two others persisted despite marked side-effects, which would have contraindicated continued use of the drug. Thus approximately half of the patients could not tolerate long-term dichlorphenamide. Dorris et al. (1964) demonstrated a fall in arterial $\mathrm{pH}$, and it would appear that the adverse symptoms may be due mainly to the metabolic disturbance, for they appear similar to the symptoms of chronic acidotic renal failure. It may be that patients with a marked initial acidosis, or who develop a marked acidosis during treatment, respond less favourably, and the occurrence of adverse symptoms could be a useful warning sign of serious acidosis.

In addition to adverse symptoms, there was a rise in blood urea and fall in plasma potassium. However, the mean values were still within normal limits at the end of a fortnight.

In summary, only about half of the patients could tolerate long-term dichlorphenamide, and in these there was an improvement in the blood gases but not in symptoms.

\section{Conclusions}

These drugs produce no symptomatic improvement, therefore there is no indication for using them if the blood gas tensions are normal, which they are in the vast majority of patients with chronic bronchitis.

Amiphenazole, in the dose used, does not appear to be of any value in the treatment of chronic respiratory failure.

The place of dichlorphenamide is more difficult to assess. It seems to produce a marked " biochemical " improvement without affecting the patient's symptoms. The raised arterial oxygen saturation could possibly postpone the onset of cor pulmonale, since hypoxia is thought to be important in its pathogenesis (Kellaway, 1959). Improved oxygenation of the tissues might also reduce the incidence or severity of acute exacerbations of the underlying bronchitis.

Against these possible long-term advances must be set the possible long-term disadvantages of a metabolic acidosis, and other possible adverse effects as yet undiscovered.

It would appear that the problem could be resolved only by a large-scale, long-term controlled study of morbidity and mortality.

In the meantime we suggest that dichlorphenamide be used only in patients who do not have side-effects. They should be closely observed, preferably with laboratory facilities, so that blood urea and potassium levels may be followed, and potassium supplements given if necessary.

\section{Summary}

A double-blind controlled therapeutic trial of amiphenazole, dichlorphenamide, and a placebo has been carried out in 12 ambulant chronic bronchitic patients with chronic respiratory failure.

Amiphenazole did not produce any significant effect.

Dichlorphenamide increased the mean arterial oxygen saturation from 86.8 to $90.9 \%$ and decreased the mean mixed venous $\mathrm{PCO}_{2}$ from 60.5 to $55.1 \mathrm{~mm}$. $\mathrm{Hg}$. These changes were statistically significant. There was no symptomatic improvement. Side-effects were frequent and severe.

Although dichlorphenamide may be of value by increasing the arterial oxygen level in preventing complications in chronic respiratory failure, the high incidence of side-effects is such that the drug should be used only under close supervision.

A long-term controlled trial with dichlorphenamide is indicated to assess its possible beneficial effects on morbidity and mortality in chronic respiratory failure.

We wish to thank Dr. J. D. Merrett, of the Department of Medical Statistics, Queen's University of Belfast, for advice in 
planning the trial ; Mr. D. Neill, of the Biochemistry Laboratory, for the electrolyte and blood urea estimations; Professor J. W. Dundee and Dr. J. A. Fisher for the loan of apparatus; and Merck Sharp \& Dohme Ltd. and Nicholas Laboratories Ltd. for co-operating to produce and supply identical tablets of the two active drugs and the placebo free of charge. We are grateful to our colleagues in the Department of Therapcutics and Pharmacology for help in referring patients, and to Professor O. L. Wade for encotragement and advice. The hyperaemic cream used in connexion with ear oxymetry was Finalgon, supplied by Pfizer Ltd. We wish to acknowledge financial help from the Wellcome Foundation, the Northern Ireland Hospitals Authority, the Royal Victoria Hospital Endowment Fund, and the Medical Research Council.
REFERENCES

Baker, H., and Pegum, J. S. (1963). Brit. med. F., 2, 1473.

Campbell, E. J. M. (1960). Ibid., 1, 457.

- and Howell, J. B. L. (1960). Ibid., 1, 458.

Dorris, R., Olivia. Ju., 2, 630.

Hughes, D. (1963). Brit. F. Dis. Chest., 57, 204.

Kellaway, G. (1959). Lancet, 2, 768.

Little, G. M. (1962). Brit. med. 7., 1, 223.

McNicol, M. W., and Pride, N. B. (1961). Lancet, 1, 906.

Naimark, A., Brodovsky, D. M., and Cherniack, R. M. (1960). Amer. F. Med., 28, 368.

Scadding, J. G. (1963). Brit. med. 7., 2, 1269.

Simpson, T. (1961). Lancet, 1, 54.

\title{
Relation Between Myasthenia Gravis and Thyroid Disease
}

\author{
B. M. SAHAY,* M.B., M.R.C.P. ; L. M. BLENDIS, $\dagger$ M.B., M.R.C.P. ; RAYMOND GREENE, $\ddagger$ M.A., D.M., F.R.C.P.
}

The relation between myasthenia gravis and thyroid disease remains unclarified. The association is thought to be uncommon, and it is generally believed that hyperthyroidism is far more commonly associated with myasthenia gravis than is hypothyroidism. However, no explanation has been offered to account for this difference. The association of myasthenia gravis and hyperthyroidism has been reported by many authors (Rennie, 1908 ; Cohen and King, 1932; Thorner, 1939 ; McEachern and Parnell, 1948 ; Greene, 1949 ; Bartels and Kingsley, 1949 ; Levy et al., 1951 ; Millikan and Haines, 1953 ; Maclean and Wilson, 1954; Silver and Osserman, 1957). Various estimates place the incidence of hyperthyroidism at from 3 to $8 \%$ in cases of myasthenia gravis. On the other hand, very few cases have been reported of the combination of myasthenia gravis and spontaneous myxoedema. Feinberg et al. (1957) reported two such cases, Greene and Artunkal (1958) one, and Storm-Mathisen (1961) two. One case of myasthenia gravis associated with Hashimoto's disease was reported recently by Daly and Jackson (1964).

There are conflicting reports on the effect of the thyroid status on myasthenia gravis. The " see-saw" relationship that is said to exist between hyperthyroidism and myasthenia gravis -myasthenia waning with hyperthyroidism and waxing with the treatment of hyperthyroidism-is supported by some authors (Thorner, 1939 ; McEachern and Parnell, 1948 ; Bartels and Kingsley, 1949 ; Maclean and Wilson, 1954), while others were unable to confirm its universal validity (Kowallis et al., 1942 ; Carson and Keynes, 1942 ; Sheldon and Walker, 1946 ; Millikan and Haines, 1953; Silver and Osserman, 1957). Drachman (1962) reported that the eumetabolic status was optimal for his athyreotic patient with myasthenia gravis and any departure from this in either the hyperthyroid or the hypothyroid range was detrimental. Engel (1961) was unable to demonstrate any improvement in patients with myasthenia gravis who were deliberately made hyperthyroid by the administration of either triiodothyronine or thyroid stimulating hormone (T.S.H.).

We report eight cases of myasthenia gravis associated with thyroid disease in which the nature of thyroid dysfunction

* Registrar, Department of Endocrinology, New End Hospital, London.
t Late House-physician, Department of Endocrinology, New End
Hospital, London. Present address: Hammersmith Hospital,
London.
$\ddagger$ Senior Physician and Medical Director, Department of Endocrinology, ¥ Senior Physician and Medical
New End Hospital, London. has been established. Of these, five were hypothyroid and three hyperthyroid.

\section{Methods and Materials}

This series extends over a period of 20 years and includes 260 cases of myasthenia gravis and over 12,000 cases of thyroid disease. All the patients with myasthenia gravis who survived the first five years of this period were examined by one of us (R. G.), who also examined the majority of patients with thyroid disease. In the past thyroid function tests were performed only in those cases of myasthenia gravis in which thyroid dysfunction was suspected; but in the last two years they were performed in all cases. These tests included the determination of the serum protein-bound iodine (Bird and Jackson, 1962), the total 48-hour urinary excretion of an orally administered dose of ${ }^{131} \mathrm{I}$, the thyroid index " $\mathrm{T}$ " (Russell Fraser, 1956), the immediate thyroidal uptake of ${ }^{131}$ I (Farran, 1958), the uptake of ${ }^{131}$ I-labelled triiodothyronine by the red blood cells (Hamolsky et al., 1959), hereinafter referred to as the T3 test, the serum cholesterol, and the B.M.R. Not all these tests were performed in every case.

All patients with myasthenia gravis and patients with thyroid disease in whom myasthenia gravis was suspected were subjected to the diagnostic tests for myasthenia gravis. These included response to intravenous injection of edrophonium chloride (Tensilon) or an intramuscular injection of neostigmine (Prostigmin), ergometry (Greene et al., 1961), the decamethonium-Tensilon test (Churchill-Davidson and Richardson, 1952), and electromyography.

\section{Case 1}

A man aged 56 was referred from another hospital in March 1963. Diabetes mellitus had been detected in 1961 and after his admission to this hospital was stabilized by 76 units of insulin zinc suspension (I.Z.S.). There was a six-month history of progressively increasing weakness and undue fatigability of the ocular, bulbar, facial, and limb muscles. On examination he had a myasthenic facies and smile, bilateral ptosis, generalized limb-muscle weakness, and fatigability. The skin was cool, dry, and rough. The deep tendon reflexes showed delayed relaxation in the upper limbs.

Investigations.-The total 48-hour ${ }^{131}$ I urinary excretion was $65 \%$ and the thyroid index 1.4. The immediate neck uptake of 